\title{
Immunooncology in Breast Cancer: Active and Passive Vaccination Strategies
}

\author{
Florian Schütz $^{a} \quad$ Frederik Marmé $^{b}$ Christoph Domschke ${ }^{a} \quad$ Christof Sohn $^{c}$ \\ Alexandra von $\mathrm{Au}^{\mathrm{a}}$ \\ a Universitätsfrauenklinik Heidelberg, Heidelberg, Germany; \\ ${ }^{b}$ Gyneco-Oncology Section, National Center of Tumor Diseases (NCT), Heidelberg, Germany; \\ ${ }^{\mathrm{c}}$ Heidelberg University Women's Hospital, Heidelberg, Germany
}

\section{Keywords \\ Immunotherapy · Vaccines · T cells · Dendritic cells}

\section{Summary}

Immunotherapies are set to become part of the therapeutic repertoire for breast cancer in the near future. Active vaccination is a promising strategy, especially in tumors that have a specific tumor-associated antigen. Although cellular immunotherapies have not yet shown efficacy, new technologies are on the way to improve this approach. Given the recent Food and Drug Administration approval of chimeric antigen receptor (CAR) $T$ cells for leukemia, it is only a question of time before solid tumors will follow. However, not all breast cancer patients will respond to cellular or other immunotherapy. Hence, we must define subpopulations of breast cancer patients who benefit from this new approach.

(C) 2018 S. Karger GmbH, Freiburg

\section{Introduction}

Over the last 3 decades, many investigators have searched for a way to treat breast cancer by using immune cells. However, until a few years ago and despite much effort having been put into oncoimmunological trials, their clinical benefit, with the exception of some encouraging preliminary results, remained disappointing. The main hurdles compromising the efficacy of these vaccination strategies are difficulties in generating broad and robust immune responses as well as overcoming immune escape mechanisms.

General interest in immunooncology was triggered when trastuzumab showed a significant benefit in a subgroup of breast cancer patients as the first antibody able to induce an antigen-specific antitumor immune reaction [1]. The main effects of trastuzumab seem to be due to immunization effects on the one hand and synergistic activity with chemotherapeutic regimens on the other hand [2]. Furthermore, we now know that radiotherapy as well as cytotoxic treatment are immunological therapies in their own right. Irradiation of tumor cells leads to an increased release of antigens with subsequent activation of immune effector cells that will affect not only the irradiated tumor but also distant non-irradiated tumors. This hypothesis is called abscopal effect and has been discussed intensively in recent journals [3].

Checkpoint inhibitors like pembrolizumab or atezolizumab were the first to show efficacy in the subgroup of triple-negative tumors. Checkpoint inhibitors augment tumor-specific responses and block suppressive pathways that tumors depend on to maintain their immune privilege. These agents have shown increasing efficacy in the treatment of non-small cell lung cancer, malignant melanoma, and bladder cancer, and interesting first results have been obtained for many other tumors like endometrial, cervical, or breast cancer. The tremendous success of checkpoint inhibition in many solid tumors brought about a renaissance in cancer immunotherapy. We have learned a lot about immunological pathways, signal transducing, and cellular interactions in solid tumors. However, despite all the efforts made to understand these mechanisms, we have only just started to translate this knowledge into therapeutic applications.

\section{Active Vaccination}

Active vaccination or immunization is defined as the use of a specific antigen to promote an antigen-specific immunoreaction inside the human body. Many diseases like poliomyelitis or measles have been eradicated in many countries worldwide by using this technique.

\section{KARGER}

(c) 2018 S. Karger GmbH, Freiburg 
An anticancer vaccination strategy seems to be encouraging in tumors with specific tumor-associated antigens (TAAs) like cervical cancer. However, in other solid tumors like breast cancer, vaccines have demonstrated very limited efficacy except for some promising preliminary results.

Autologous tumor vaccines using patient-derived tumor cells represent one of the first types of cancer vaccines to be tested [4]. These tumor cells were typically irradiated, combined with an immunostimulatory adjuvant (e.g., Bacillus Calmette-Guerin), and then administered to the individual from whom the tumor cells were isolated [5]. Another approach was the use of allogenic tumor cell vaccines to induce a long-lasting antitumor immune response [6]. However, despite an intensive search of published trials, we were unable to find any successful study in breast cancer patients. A rapidly increasing and improved understanding of tumor immune escape mechanisms and promising strategies to confront these in the last 10-20 years have raised new hope and led to new approaches.

One of the basic characteristics of a tumor vaccine is that it has to be distinguished from self-antigens by the host's immune system and identified as foreign. It has been recognized that the immune system is capable of recognizing several types of antigens on tumor cells referred to as TAAs. In contrast to other cytotoxic therapies, cancer vaccines have demonstrated minimal toxicity in all clinical trials reported to date. Despite expression of many target TAAs in normal tissues, little evidence of autoimmunity has been observed, with the exception of vitiligo in patients receiving certain melanoma vaccines. Cancer vaccine antigens can be administered via several possible platforms, such as peptides, proteins, naked DNA, viral vectors, whole cell-based vaccines (autologous, heterologous), and dendritic cell(DC)-based vaccines [7]. In most vaccination strategies, antigen delivery is combined with the co-administration of an adjuvant to enhance the immune response [8].

\section{Peptide-Based Vaccination}

Peptide vaccines have advantages as well as disadvantages: ease of manufacture, easily evaluated immune response, and a favorable toxicity profile but restricted to HLA-A2 limiting the number of patients. Protein/peptide-based vaccines are more cost-effective than autologous or individualized vaccines. However, a potential drawback is that they target only one or a few epitopes of the TAA. It is generally assumed that an induction of both antigen-specific cytotoxic T lymphocytes and antigen-specific CD4+ helper T cells is necessary for a cancer vaccine to be optimally efficacious. In the following, we discuss vaccination strategies with the most studied and well-described antigens.

\section{Anti-HER2 Vaccines}

HER2-directed vaccines are the most intensively studied for breast cancer. Several HER2-directed vaccines are currently undergoing clinical development. The HER2 peptide E75 vaccine (nelipepimut-S; NeuVax ${ }^{\mathrm{TM}}$, Galena Biopharma, San Ramon, CA, USA) (aa 369-377), derived from the extracellular domain, is the most studied in the clinical setting. It is limited to HLA-A2+ patients. Final results from a phase I/II trial including 195 women with early breast cancer and an immunohistochemical HER2 expression score of at least 1 were reported. Patients screened negative for HLA-A2/3 within the trial served as a control group. 5-year disease-free survival (DFS) in vaccinated patients was $89.7 \%$ compared to $80.2 \%$ among controls $(\mathrm{p}=0.08)$. Patients receiving a booster inoculation $(n=53)$ showed an even higher 5 -year DFS (95.2\%; $\mathrm{p}=0.11$ ) compared to controls. The results of the completed phase III trial (PRESENT, NCT01479244) are eagerly awaited. Further trials combining E75 with trastuzumab are ongoing (NCT01570036).

Another HER2-directed vaccine (GP2 peptide, a 9-amino acid peptide from the transmembrane domain of HER2 (aa654-662) also restricted to HLA-A2) has also been evaluated in a randomized phase II trial $(\mathrm{n}=170$; NCT00524277). Early results suggest an improved DFS in vaccinated patients compared to controls if early-relapse patients (within the first 6 months) are excluded (94 vs. $85 \% ; \mathrm{p}=0.1)[9,10]$.

\section{Anti MUC-1 Vaccines}

Most peptide-based vaccines in clinical trials target cancer/testis antigens, differentiation-associated antigens, or certain oncofetal antigens (CEA, MUC-1). Although these vaccines were able to induce antigen-specific $\mathrm{T}$-cell responses, clinical outcomes have been disappointing [11]. The membrane glycoprotein MUC-1 is frequently found to be overexpressed on cancer cells and can be used as a cancer vaccine as well if applied in the abnormally glycosylated form. The presence of specific antibodies in patients with early breast cancer has been associated with improved survival [12]. A synthetic antigen conjugated to a special carrier (STn-KLH; Theratope $^{\mathrm{TM}}$, Biomira, Inc., Edmonton, $\mathrm{AB}$, Canada) was used as a vaccine in a large randomized phase III trial in patients with metastatic breast cancer either in remission or with stable disease after first-line treatment ( $n=1,028$; completed). Although the vaccine produced strong humoral responses, there was no DFS or overall survival (OS) benefit. However, in the estrogen receptor-positive subgroup, a significant OS benefit was observed [13].

A further MUC-1-derived vaccine induced both cytotoxic and humoral responses in a small randomized pilot study. Despite the small numbers $(\mathrm{n}=31)$, the vaccine significantly reduced the recurrence rate (60.5 vs. $12 \%$; $\mathrm{p}=0.002)[14,15]$.

PANVAC $^{\mathrm{TM}}$ (Therion Biologics Corp., Cambridge, MA, USA) targets both MUC-1 and CEA; it uses viral vectors to deliver the antigen together with 3 human $\mathrm{T}$-cell costimulatory molecules [16]. In early clinical trials in heavily pretreated patients, the vaccine demonstrated some clinical activity, including a complete response $[17,18]$.

\section{Other Breast Cancer Antigens}

MAGE-A3 and NY-ESO-1, which have already been tested in lung cancer and melanoma, are also preferentially expressed in triple-negative breast cancer. Here, they seem to also be highly immunogenic, and immune response is associated with tumor-infil- 
trating lymphocytes (TILs) and a favorable prognosis [19, 20]. These antigens remain potential targets for breast cancer immunotherapy.

NY-BR1, Mammoglobin-A, hTERT, and WT-1 are further cancer antigens and candidates for clinical vaccination trials.

\section{Genetic Vaccines}

Antigen or antigen fragments can also be delivered in vivo via viral or plasmid DNA vectors expressing specific antigens that will activate the immune system. Upon administration, they transfect somatic cells like myocytes or DCs that infiltrate muscle or skin as part of the inflammatory response to vaccination, resulting in a subsequent cross-priming or direct antigen presentation. Genetic vaccines can be administered easily and may include multiple antigens in a single immunization and activation of various arms of immunity [21].

\section{DNA-Based Vaccines}

DNA-based vaccines use another mechanism of action. Uptake of the DNA encoding for the selected TAA by antigen-presenting cells (APCs) leads to subsequent translation into protein, followed by intracellular processing and presentation. DNA vaccines can be administered as naked DNA, complexed with other molecules, as liposomal formulations, or incorporated into nanoparticles [22, 23]. This technique has not been used clinically in breast cancer. However, in mice, some success has been shown [24]. It has also been shown that DNA vaccines can be rationally combined with other immunostimulatory agents, such as Toll-like receptor agonists, to optimize antibody responses.

Vaccines Based on Viral Vectors for Antigen Delivery

A further vaccination strategy consists of viral vectors (e.g. Newcastle virus, poxvirus family members, measles, and adenoviral vectors). Vectors produce longer-lasting and broader immunity than both naked DNA and peptide vaccines. Especially the application of costimulatory molecules at the same time to enhance the immune response make them interesting for vaccination strategies. In prostate cancer, an OS benefit has been shown with the viral cancer vaccine PROSTVAC (Bavarian Nordic, Kvistgaard, Denmark), which is a platform consisting of a replication-competent vaccinia priming vector and a replication-incompetent fowlpox boosting vector [25]. Each vector contains transgenes for prostatespecific antigen and 3 costimulatory molecules (CD80, CD54, and CD58). However, to our knowledge, there is currently no recruiting clinical trial for breast cancer.

\section{Cell-Based Active Vaccination}

\section{APC-Based Vaccination}

DCs are the most important APCs characterized by high density of major histocompatibility complex molecules as well as costimu- latory molecules. DC-based vaccines are not human leukocyte antigen(HLA)-restricted and can stimulate both class I and II responses. DCs can be generated easily from peripheral blood mononuclear cells, e.g. via apheresis. DCs can subsequently be loaded with antigens (proteins, peptides, and cell lysates) or transfected with TAA-carrying vectors [26]. An experimental DC-based HER2targeted version of Sipuleucel-T (Lapuleucel-T; Neuvenge ${ }^{\mathrm{TM}}$, Dendreon, Seal Beach, CA, USA) has demonstrated limited activity in breast cancer. Several HER2-pulsed DC-based vaccines have been investigated in a variety of settings including ductal carcinoma in situ [27-29]. However, DC-based vaccines remain technically challenging with regards to large-scale manufacturing including in vitro expansion, maturation, and activation [30].

\section{Passive Vaccination}

Passive vaccination or immunization describes the transfer of active humoral immunity in the form of ready-made antibodies or effector lymphocytes like activated T cells and natural killer (NK) cells.

Huge efforts are being made to find ready-made antibodies like trastuzumab and pertuzumab for HER2-positve breast cancer to treat tumor cells specifically and effectively. However, finding an antibody that has antitumor effects is like finding a needle in the haystack on the one hand while winning the jackpot on the other hand.

Many approaches to cellular immunotherapy have been described most of which failed, generally due to a lack of standardized and reproducible study protocols, high costs, and, in the end, lacking efficacy in the treatment of breast cancer. However, new approaches, especially to switching off immune escape, have led to a renaissance in cellular immunotherapy. A classic example of this type of therapy is the adoptive T-cell transfer in malignant melanoma, in which peritumoral $\mathrm{T}$ cells are extracted and activated and propagated outside the body. After transfer of these activated $\mathrm{T}$ cells, a long-lasting response could be detected in over $25 \%$ of the tumors [31].

Our own working group has performed a trial with adoptive Tcell transfer in metastatic breast cancer patients. Here, tumor antigen-specific CD8+ T cells derived from bone marrow were activated ex vivo and then re-administered to the patients intravenously. There was a remarkable immunological response in half of the patients [32]. These responders also showed markedly prolonged OS in comparison to non-responders, although the absolute number of patients was low [33]. However, it seems that immune escape mechanisms that had not been addressed before $\mathrm{T}$ cell application prohibited a clinically effective tumor regression.

Although NK cells could also be used for passive vaccination, they do not seem to have the same potential as T cells $[34,35]$. However, in the last few years, several reports has been published about stem cell-derived NK cells that may have a better cytotoxic effect against tumor cells [36, 37]. Furthermore, the combination with chemotherapy might lead to higher responses in metastatic breast cancer patients [38]. 
Another interesting approach is the adoptive cell transfer with chimeric antigen receptor (CAR) T cells. In this setting, $\mathrm{T}$ cells are taken from a patient and are infected with genes encoding a T-cell receptor (TCR) directed against a TAA. These genes are integrated in the patient's genome. The artificial TCR will be replicated and expressed on the T-cell surface initiating an immune response that kills the targeted cell. In leukemia patients, the Food and Drug Administration has approved CAR T cells as the first cellular immu- notherapy due to clinical benefit in randomized trials [39]. Whether this type of T-cell therapy can also play a role in other cancers will become apparent in the next few years [40].

\section{Disclosure Statement}

The authors do not have any conflict of interest to declare.

\section{References}

1 Slamon DJ, Leyland-Jones B, Shak S, Fuchs H, Paton V, Bajamonde A, Fleming T, Eiermann W, Wolter J, Pegram M, Baselga J, Norton L: Use of chemotherapy plus a monoclonal antibody against HER2 for metastatic breast cancer that overexpresses HER2. N Engl J Med 2001;344:783-792.

2 Moasser MM: Two dimensions in targeting HER2. J Clin Oncol 2014;32:2074-2077.

3 Brix N, Tiefenthaller A, Anders H, Belka C, Lauber K Abscopal, immunological effects of radiotherapy: narrowing the gap between clinical and preclinical experiences. Immunol Rev 2017;280:249-279.

4 Hanna MG Jr, Peters LC: Specific immunotherapy of established visceral micrometastases by BCG-tumor cell vaccine alone or as an adjunct to surgery. Cancer 1978;42:2613-2625.

5 Berger M, Kreutz FT, Horst JL, Baldi AC, Koff WJ: Phase I study with an autologous tumor cell vaccine for locally advanced or metastatic prostate cancer. J Pharm Pharm Sci 2007;10:144-152.

6 Emens LA, Asquith JM, Leatherman JM, Kobrin BJ, Petrik S, Laiko M, Levi J, Daphtary MM, Biedrzycki B, Wolff AC, Stearns V, Disis ML, Ye X, Piantadosi S, Fetting JH, Davidson NE, Jaffee EM: Timed sequential treatment with cyclophosphamide, doxorubicin, and an allogeneic granulocyte-macrophage colony-stimulating factor-secreting breast tumor vaccine: a chemotherapy dose-ranging factorial study of safety and immune activation. J Clin Oncol 2009;27:5911-5918.

7 Luiten RM, Kueter EW, Mooi W, Gallee MP, Rankin EM, Gerritsen WR, Clift SM, Nooijen WJ, Weder P, van de Kasteele WF, Sein J, van den Berk PC, Nieweg OE, Berns AM, Spits H, de Gast GC: Immunogenicity, including vitiligo, and feasibility of vaccination with autologous GM-CSF-transduced tumor cells in metastatic melanoma patients. J Clin Oncol 2005;23:89788991.

8 Ernst B, Anderson KS: Immunotherapy for the treatment of breast cancer. Curr Oncol Rep 2015;17:5.

9 Schneble EJ, Perez SA, Murray JL, Berry JS, Trappey AF, Vreeland TJ, Hale DF, Greene JM, Clifton GT, Ardavanis A, Litton JK, Ponniah S, Shumway NM, Papamichail M, Peoples GE, Mittendorf EA: Primary analysis of the prospective, randomized, phase II trial of GP2+GM-CSF vaccine versus GM-CSF alone administered in the adjuvant setting to high-risk breast cancer patients. J Clin Oncol 2014;32:134.

10 Trappey F, Berry JS, Vreeland TJ, Hale DF, Sears AK, Ponniah S, Perez SA, Clifton GT, Papamichail M, Peoples GE, Mittendorf EA: Randomized phase II clinical trial of the anti-HER2 (GP2) vaccine to prevent recurrence in high-risk breast cancer patients: a planned interim analysis. J Clin Oncol 2013;31:3005.
11 Buonaguro L, Tagliamonte M, Tornesello ML, Buonaguro FM: Developments in virus-like particle-based vaccines for infectious diseases and cancer. Expert Rev Vaccines 2011;10:1569-1583.

12 Blixt O, Bueti D, Burford B, Allen D, Julien S, Hollingsworth M, Gammerman A, Fentiman I, Taylor-Papadimitriou J, Burchell JM: Autoantibodies to aberrantly glycosylated MUC1 in early stage breast cancer are associated with a better prognosis. Breast Cancer Res 2011;13:R25.

13 Miles D, Roche H, Martin M, Perren TJ, Cameron DA, Glaspy J, Dodwell D, Parker J, Mayordomo J, Tres A, Murray JL, Ibrahim NK, Theratope Study G: Phase III multicenter clinical trial of the sialyl-TN (STn)-keyhole limpet hemocyanin $(\mathrm{KLH})$ vaccine for metastatic breast cancer. Oncologist 2011;16:1092-1100.

14 Apostolopoulos V, Pietersz GA, Tsibanis A, Tsikkinis A, Drakaki $\mathrm{H}$, Loveland BE, Piddlesden SJ, Plebanski M, Pouniotis DS, Alexis MN, McKenzie IF, Vassilaros S: Pilot phase III immunotherapy study in early-stage breast cancer patients using oxidized mannan-MUC1 (ISRCTN71711835). Breast Cancer Res 2006;8:R27.

15 Vassilaros S, Tsibanis A, Tsikkinis A, Pietersz GA, McKenzie IF, Apostolopoulos V: Up to 15-year clinical follow-up of a pilot phase III immunotherapy study in stage II breast cancer patients using oxidized mannanMUC1. Immunotherapy 2013;5:1177-1182.

16 Parkhurst MR, Riley JP, Igarashi T, Li Y, Robbins PF, Rosenberg SA: Immunization of patients with the hTERT:540-548 peptide induces peptide-reactive $t$ lymphocytes that do not recognize tumors endogenously expressing telomerase. Clin Cancer Res 2004; 10:4688-4698.

17 Gulley JL, Arlen PM, Tsang KY, Yokokawa J, Palena C, Poole DJ, Remondo C, Cereda V, Jones JL, Pazdur MP, Higgins JP, Hodge JW, Steinberg SM, Kotz H, Dahut WL, Schlom J: Pilot study of vaccination with recombinant CEA-MUC-1-TRICOM poxviral-based vaccines in patients with metastatic carcinoma. Clin Cancer Res 2008;14:3060-3069.

18 Mohebtash M, Tsang KY, Madan RA, Huen NY, Poole DJ, Jochems C, Jones J, Ferrara T, Heery CR, Arlen PM, Steinberg SM, Pazdur M, Rauckhorst M, Jones EC, Dahut WL, Schlom J, Gulley JL: A pilot study of MUC-1/CEA/TRICOM poxviral-based vaccine in patients with metastatic breast and ovarian cancer. Clin Cancer Res 2011;17:7164-7173

19 Ademuyiwa FO, Bshara W, Attwood K, Morrison C, Edge SB, Karpf AR, James SA, Ambrosone CB, O'Connor TL, Levine EG, Miliotto A, Ritter E, Ritter G, Gnjatic S, Odunsi K: NY-ESO-1 cancer testis antigen demonstrates high immunogenicity in triple negative breast cancer. PloS One 2012;7:e38783.
20 Lee HJ, Kim JY, Song IH, Park IA, Yu JH, Gong G: Expression of NY-ESO-1 in triple-negative breast cancer is associated with tumor-infiltrating lymphocytes and a good prognosis. Oncology 2015;89:337-344.

21 Aurisicchio L, Ciliberto G: Genetic cancer vaccines: current status and perspectives. Expert Opin Biol Ther 2012;12:1043-1058.

22 Trimble CL, Morrow MP, Kraynyak KA, et al: Safety, efficacy, and immunogenicity of VGX-3100, a therapeutic synthetic DNA vaccine targeting human papillomavirus 16 and 18 E6 and E7 proteins for cervical intraepithelial neoplasia 2/3: a randomised, doubleblind, placebo-controlled phase $2 \mathrm{~b}$ trial. Lancet 2015; 386:2078-2088.

23 Yan J, Pankhong P, Shin TH, Obeng-Adjei N, Morrow MP, Walters JN, Khan AS, Sardesai NY, Weiner DB: Highly optimized DNA vaccine targeting human telomerase reverse transcriptase stimulates potent antitumor immunity. Cancer Immunol Res 2013;1:179-189.

24 Aurisicchio L, Peruzzi D, Conforti A, Dharmapuri S, Biondo A, Giampaoli S, Fridman A, Bagchi A, Winkelmann CT, Gibson R, Kandimalla ER, Agrawal S, Ciliberto G, La Monica N: Treatment of mammary carcinomas in HER-2 transgenic mice through combination of genetic vaccine and an agonist of Toll-like receptor 9. Clin Cancer Res 2009;15:1575-1584.

25 Kantoff PW, Gulley JL, Pico-Navarro C: Revised overall survival analysis of a phase II, randomized, doubleblind, controlled study of PROSTVAC in men with metastatic castration-resistant prostate cancer. J Clin Oncol 2017;35:124-125.

26 Shang N, Figini M, Shangguan J, Wang B, Sun C, Pan L, Ma Q, Zhang Z: Dendritic cells based immunotherapy. Am J Cancer Res 2017;7:2091-2102.

27 Baek S, Kim CS, Kim SB, Kim YM, Kwon SW, Kim Y, Kim H, Lee H: Combination therapy of renal cell carcinoma or breast cancer patients with dendritic cell vaccine and IL-2: results from a phase I/II trial. J Transl Med 2011;9:178.

28 Koski GK, Koldovsky U, Xu S, Mick R, Sharma A, Fitzpatrick E, Weinstein S, Nisenbaum H, Levine BL, Fox K, Zhang P, Czerniecki BJ: A novel dendritic cellbased immunization approach for the induction of durable Th1-polarized anti-HER-2/neu responses in women with early breast cancer. J Immunother 2012; 35:54-65.

29 Sharma A, Koldovsky U, Xu S, Mick R, Roses R, Fitzpatrick E, Weinstein S, Nisenbaum H, Levine BL, Fox K, Zhang P, Koski G, Czerniecki BJ: HER-2 pulsed dendritic cell vaccine can eliminate HER-2 expression and impact ductal carcinoma in situ. Cancer 2012;118: 4354-4362. 
30 Milani A, Sangiolo D, Aglietta M, Valabrega G: Recent advances in the development of breast cancer vaccines. Breast Cancer (Dove Med Press) 2014;6:159-168.

31 Goff SL, Dudley ME, Citrin DE, et al: Randomized, prospective evaluation comparing intensity of lymphodepletion before adoptive transfer of tumor-infiltrating lymphocytes for patients with metastatic melanoma. J Clin Oncol 2016;34:2389-2397.

32 Schuetz F, Ehlert K, Specht S, Schneeweis A, Rom J, Sohn C, Schirrmacher V, Beckhove P: First phase I clinical study of adoptive cellular cancer immunotherapy with autologous bone-marrow derived tumor antigen reactive memory $\mathrm{T}$ cells: feasibility, toxicity and immunological effects. Cancer Immunol Immunother 2008;58:887-900.

33 Domschke C, Ge Y, Bernhardt I, Schott S, Keim S, Juenger S, Bucur M, Mayer L, Blumenstein M, Rom J, Heil J, Sohn C, Schneeweiss A, Beckhove P, Schuetz F: Long-term survival after adoptive bone marrow $\mathrm{T}$ cel therapy of advanced metastasized breast cancer: follow-up analysis of a clinical pilot trial. Cancer Immunol Immunother 2013;62:1053-1060.
34 Parkhurst MR, Riley JP, Dudley ME, Rosenberg SA: Adoptive transfer of autologous natural killer cells leads to high levels of circulating natural killer cells but does not mediate tumor regression. Clin Cancer Res 2011;17:6287-6289.

35 Granzin M, Wagner J, Köhl U, Cerwenka A, Huppert V, Ullrich E: Shaping of natural killer cell antitumor activity by ex vivo cultivation. Front Immunol 2017;8: 458.

36 Eguizabal C, Zenarruzabeitia O, Monge J, Santos S, Vesga MA, Maruri N, Arrieta A, Riñón M, TamayoOrbegozo E, Amo L: Natural killer cells for cancer immunotherapy: pluripotent stem cells-derived NK cells as an immunotherapeutic perspective. Front Immunol 2014;5:43.

37 Nham T, Poznanski SM, Fan IY, Vahedi F, Shenouda MM, Lee AJ, Chew MV, Hogg RT, Lee DA, Ashkar AA: Ex vivo-expanded natural killer cells derived from long-term cryopreserved cord blood are cytotoxic against primary breast cancer cells. J Immunother 2017;DOI: 10.1097/CJI.0000000000000192.
38 Gebremeskel S, Lobert L, Tanner K, Walker B, Oliphant T, Clarke LE, Dellaire G, Johnston B: Natural killer T-cell immunotherapy in combination with chemotherapy-induced immunogenic cell death targets metastatic breast cancer. Cancer Immunol Res 2017;5:1086-1097.

39 Schwarzbich MA, Witzens-Harig M: Cellular immunotherapy in B-cell malignancy. Oncol Res Treat 2017; 40:674-681.

40 Xia AL, Wang XC, Lu YJ, Lu XJ, Sun B: Chimeric-antigen receptor $\mathrm{T}$ (CAR-T) cell therapy for solid tumors: challenges and opportunities. Oncotarget 2017;8: 90521-90531. 